Journal of Social Sciences 5(2): 104-111, 2009

ISSN 1549-3652

(C) 2009 Science Publications

\title{
Personal and Psychological Factors-Does it Impact the Choice of Advertising Medium?
}

\author{
Izian Idris, Mohd Shukri Ab Yajid and Ali Khatibi \\ Faculty of Business and Professional Study, Management Science University, \\ Jalan Equestrian 13/1, 40000 Shah Alam, Selangor, Malaysia
}

\begin{abstract}
Problem statement: Advertising is a multidimensional phenomenon that has been studied in several disciplines. It is one of the most fascinating phenomena in modern capitalist markets. It is pervasive, perplexing, multidimensional and unfathomably rich. The effectiveness of advertising depends on both the quality of the product being advertised and the quality of the ad itself and also the media context in which the ad appears. Personal factors (such as gender and age) and psychological factors (for example status and personality) may affect the choice of advertising medium. Consumers' interest may change due to these factors. The analysis had proved that both factors do impact the choice of advertising medium. The study may help marketers, advertisers and businesses to create and come out with suitable advertisements that suits the interests of consumers' derived from those factors. It may help them to choose suitable advertising media for different target market. The study searched for to find out whether personal and psychological factors have any impact to the choice of advertising medium. Approach: For this study purposes, questionnaires and copy testing had been used to addresses issues related to the effectiveness of each advertisement. About 100 printed questionnaires were distributed among respondents which comprised age from 18 years old and above where 30 respondents were tested for copy testing from all mediums, online and traditional where these respondents were given a series of all advertisements from newspaper, magazine, TV, radio, Internet, SMS and MMS. Results: The coefficient analysis showed that both personal and psychological factors had positive relationship with customer satisfaction. Between these two factors, personal factors had high level of significant relationship $(p=0.000)$ compared to psychological factors $(p=0.087)$. The analysis had proved that both factors do impact the choice of advertising medium. Conclusion: The study showed that both personal and psychological factors can lead consumers to choose different types of media. The study provided the insight to help businesses, advertisers and marketers to understand the best medium to suit the consumers' interest.
\end{abstract}

Key words: Personal factors (age and gender), psychology factors (status and personality), advertising, consumer behavior

\section{INTRODUCTION}

Personal factors and psychological factors may create different perception towards different media. For example, according to Chang ${ }^{[9]}$ gender may play an important role in determining the relative effectiveness of comparative and non-comparative advertising appeals. Nowadays, people are moving towards online advertising, mobile advertising or well known as wireless advertising. Mobile marketing provides new revenue streams and opportunities for subsidized access, along with the potential for customers to experience more convenient and relevant content value, sponsored by advertising ${ }^{[3]}$. Attitude towards ads is conceptualized as a consequence of two psychological motives in wireless internet adoption: Perceived infotainment and perceived irritation ${ }^{[39]}$. Psychological factors such as status and personality have droved the consumers' to go for different types of advertising medium. Consumer acceptance and their perceptions of the delivered content of wireless advertising are crucial $^{[6]}$.

Understanding consumers is a basic tenet of marketing and advertising ${ }^{[5]}$. The integration of advertising medium between traditional and online advertising also has become more and more popular nowadays. Newspaper websites are attracting a lot of readers and is considered a lucrative online ADEX (advertising expenditure) market ${ }^{[1]}$. All media companies-newspapers, magazines, broadcasters, 
service providers, yellow pages and pure-plays that operate exclusively online-are looking to monetize their digital information with both display advertising and performance advertising

Literature review: All consumers' have their own favorite advertising medium. Some people prefer television commercials (especially children) and there are people who prefer new types of advertising. For example wireless advertising. Okazaki ${ }^{[39]}$ claim most of the Japanese mobile users are willing to use wireless advertising and keen to 'click' such ads. In fact nowadays most people around the world are able to receive wireless advertisements since most people own mobile phones. Age, gender, personality have always being used in many study to see whether it affect consumer behavior. Unlike other media, however, advertising is more pervasive in people's lives, increasing the likelihood that consumers outside a target market will be exposed to messages that are not intended for their viewing. It is increasingly simple for these consumers to pass along negative word-of-mouth through web logs ("Blogs") and other new media technologies ${ }^{[11]}$. Understanding consumers' personal and psychological factors perspective is particularly important and may possess strong purchase influence behavior and brand recall towards the product, services and companies.

Advertising as marketing tools: Advertising is an important part to the marketers for promotional mix. Its helps in creating brand image and product awareness. Advertising is one of the most popular tools that are used by the companies for convince and communicate with the target buyers and customers.

There are many different ways of defining advertising and whether it is the traditional way, or its interactive part, definitions vary from mindset to mindset. Whether in the form of online or traditional, the purpose of advertisement will be to persuade and attract people to the product, services or even brand. Not only must the advertisement effectively communication the desired message, but the individual audience must be willing to "buy into" the desired message. In other words, for the advertisement to be effective, the communication must be sent and received.

The designation of advertising certainly reflects the claimed desire of most marketing practitioners to communicate openly and honestly with consumers. Indeed the law in most countries forbids false or deceptive advertising. Marketers justify advertising by arguing that advertising is intrinsic to markets and fundamentally beneficial to the customer ${ }^{[25]}$.
Jaishri and Shruti ${ }^{[25]}$ cited that advertising is one of the largest generators of revenue in the world economy. It moves markets and minds. It generates employment both directly and indirectly and influences a large section of the people. Advertising interests, entices, intrigues and entertains. It creates lifestyles. It involves people with products; it aims at building relationships between customers and brands.

The effects of attitudes toward the media and subsequent influence on the attitudes toward advertising in the media cannot be underestimated. A key assumption in the theory of uses and gratifications was that audiences have individual needs (i.e., cognitive, affective, interactive and many more. Motivating them to be in favor of one medium over another one when making a choice for media use. Attitudes toward media, therefore, were developed in the selecting process ${ }^{[42]}$.

The technique of advertising is to correlate feelings, moods or attributes to tangible objects, linking possible unattainable things with those that are attainable and thus reassuring us that the former are within reach" [47]. For managers, this study underlines the need to avoid misleading advertising messages in the first place. Revelations of deceptive advertising have the power to adversely affect advertising as a whole, not just the specific firm involved in the deception. For regulators, the findings suggest that careful consideration must be given to the punitive effects that such practices can have by reinforcing negative attitudes toward advertising as a whole ${ }^{[14]}$.

William, Sandra, John and May ${ }^{[46]}$ declare that persuasion sometimes uses the psychological appeal of the product to the consumer as the focus of a message strategy. An appeal connects with some emotion that makes the product particularly attractive or interesting, such as security, esteem, fears, sex and sensory pleasure. Although emotion is at the base of most appeals, in some situations appeals can also be logical, such as saving money for retirement. Appeals generally pinpoint the anticipated response of the audience to the product and the message. For example, if the price is emphasized in the ad, then the appeal is value, economy or savings. If the product saves time or effort, then the appeal is convenience. Advertisers use a status appeal to establish something as a high quality, expensive product.

Gender and age roles: Most basic research has revealed that males and females respond differently to the images they see in print, television, radio and internet and wireless advertisements. There has been considerable recent interest in the possible contributions of the mass media to the origins and maintenance of 
gender roles $^{[12,13,16,19,20,29,38]}$. For example, notes that it is regarded as more effective to target men with advertisements classed as neutral, because males will not use products even vaguely regarded as 'feminine', while women are more likely to use those products normally classed as 'male ${ }^{[45]}$ Due to this extensive exposure to mass media depictions, the media's influence on gender role attitudes has become an area of considerable interest and concern in the past quarter century. Analyses of gender portrayals have found predominantly stereotypic portrayals of dominant males and nurturant females within the contexts of advertisements (print and television), magazine fiction, newspapers, child-oriented print media, textbooks, literature, film and popular music ${ }^{[17,30,33,40,41,44]}$ proposed that individuals' attitudes can vary, depending on the current context and the information that is salient in it. For many relatively complex attitudinal topics, including gender role attitudes, people are likely to possess a mixture of relevant knowledge and beliefs, not all of which are mutually compatible ${ }^{[48]}$. The attitude that one holds at any given time will depend in part on which subset of information is most salient at the moment. Although these context-induced attitudinal shifts may not always be of great magnitude, they indicate that attitudes are relatively dynamic entities ${ }^{[22]}$. For women, ads are often more detailed. Take for example toiletry ads. For one thing, women are more concerned about grooming and appearance. And they appreciate fine distinctions where for men, by contrast, toiletry ads focus on a single product. Men are likely to pick up one or two very salient and obvious kinds of clues. Men think in a more macro way and need to be shown the big picture. Furthermore, men are less likely to process complex metaphors ${ }^{[49]}$. This statement basically is not only supporting the personal factors but also psychological factors where gender and personality of consumers can create different perceptions about the advertisements.

The need and desire to buy and sell are integral parts of human life. But advertising does not sell, anymore than anything sells itself. Someone has to look the customer in the eye and ask a closing question to make a sale, which advertising is incapable of doing. What advertising can do is stir a potential customer to action and make a current customer feel good enough about his/her choice to ensure the individual becomes a repeat customer ${ }^{[36]}$.

Age perception is a multidimensional construct ${ }^{[2]}$. The elements of an effective, age friendly advertisement range from the message to the type style to the image and more. Adopted from Milner ${ }^{[36]}$, during the interview session with Snyder a senior partner at J.
Walter Thompson's Mature Market Group, messages that motivate younger consumers do not always resonate with older consumers. The best ads for the mature market are those that specifically address their unique needs and wants. The media are also an important part of young teens' lives--they watch television, listen to music and read magazines practically every day. In addition, young people, especially those between 10 and 15, are faced with the turmoil and changes of puberty and early adolescence. Their bodies are changing, their faces are breaking out, they have mood swings, they have conflicts with their parents and others in authority roles and sometimes they wonder where they truly fit in. They often turn to each other and to the media to find the answers to their questions about how they can solve problems, how they should act, how they should behave with the opposite sex, what they should wear and what they should look like ${ }^{[43]}$. As additional, wireless advertisements such as SMS (Short Message Services) has becoming popular for all ages. Dickinger, Haghirian, Murphy and Scharl $^{[15]}$ state that text message services have been hugely popular for interpersonal communication, allowing users of all ages to exchange messages with both social and business contacts

Status and personality roles: Psychology in advertising has long been used as an effective means to sell a product or service. Understanding the underlying concepts that affect human psychology can help a company better sell their product or alternatively can help a consumer understand marketing strategies that get them to buy products ${ }^{[23]}$. To learn about psychology factors can be a good formula in advertising. Fortin ${ }^{[21]}$ claim that the competent advertising is we must understand psychology. The more we know about it the better. We must learn that certain effects lead to certain reactions and use that knowledge to increase results and avoid mistakes. Advertisers need to better understand the personality and status of the consumers in particular region, place or maybe country to come out with more effective advertising medium that able to catch the eyes and interest of the consumers. There are many ways to show the personality and status of the consumers. Those who are medium to high status probably prefer wireless advertising because they can afford to have computer with internet or mobile phone. One of the main challenges and opportunities for mobile advertising companies is to understand and respect the personal nature of the usage of mobile phones ${ }^{[24]}$. Messages that are short and concise, funny, interactive, entertaining and relevant to the target group usually achieve higher levels of success ${ }^{[26]}$ However, it was 
found that another aspect of consumers' acceptance of mobile advertising was their wish to control other aspects of the communication, such as the content, time and frequency of messages ${ }^{[7]}$.

And those who are intellectual probably are fond to read newspapers and aware of advertisements from it plus it is more cheaper to consume or prescribe newspaper. Not to be forgotten, most people around the world nowadays have their own television and commercial TV can be their first attraction. In most developed countries television has the widest audience of any medium. It is watched by all types of people regardless of national origin, race, social class, gender or age and it is watched very frequently ${ }^{[38]}$.

Another angle that needs to be understood by marketers and advertisers is models are able to play an important role in advertising. For example, portrayals of models in advertisements can suggest the lifestyle and image of product users. Moreover, extrinsic features of models, such as race and gender, have been shown to trigger a self-categorization process ${ }^{[34]}$. Chang $^{[8]}$ purport that when watching commercials or reading advertisements, consumers may categorize and advertised product as "for-me" or "not-for-me" based on these extrinsic cues. Theory by Kelman ${ }^{[27]}$ suggests that a person is more likely to adopt an attitude or behavior of another person or a group if he/she identifies with the person. Indeed, Friedman and Friedman $^{[18]}$, found that print advertisements for promoting products high in psychological and/or social risk featuring a celebrity were evaluated more favorably than those using an expert or a typical consumer and that the celebrity was more effective in getting consumers to buy the product.

\section{MATERIALS AND METHODS}

Advertising effectiveness is a crucial concern to most companies and advertisers. Advertising serves multiple purposes. It provides information, it can generate favorable attitudes toward a brand, it can lead to favorable intentions to buy, it can cause an individual to buy a brand and as is typically the case with durable purchases, it can be used rationalize a purchase. As for this research, both qualitative and quantitative method will be used. Qualitative and quantitative research in combination can provide rich insight that can help in formulating successful marketing strategies ${ }^{[35]}$.

On the basis of this research methodology data will be collected that is necessary to obtain answers to the research questions. For data collection processes, two research methodologies were selected, which were questionnaires survey and observation. Hundred printed questionnaires were distributed among respondents which comprised age from 18 years old and above. Self-completion questionnaire will be used where respondents must read and answer the questions themselves without the presence of interviewer. The research instruments have been designed easily for respondents to answer since there is no interviewer present during the administration of the self completion questionnaires. The designs of the questionnaires were based on Likert Scale ${ }^{[31]}$ as a method and multiple choices

For this study purposes, copy testing has been used to addresses issues related to the effectiveness of each advertisement. According to Kinnear and Taylor ${ }^{[28]}$ copy testing is used in practice to refer to all aspects (color, graphics, pictures, action and so on) of ads appearing in all media. It is based on a model of human response to communication. It is based on a model of human response to communication to know the reception of a stimulus, the comprehension of the stimulus and the response to the stimulus. It allows for consideration of whether the advertising stimulus should be exposed more than once. This will able to identify consumers' perceptions and interest whether personal factors (i.e., age and gender) and psychological factors (i.e., status and personality) whether its impact the choice of advertising medium.

Thirty respondents were tested from all mediums, online and traditional where these respondents are given a series of all advertisements from newspaper, magazine, TV, radio, Internet, SMS and MMS. They were first asked to complete the questionnaire. Then they were given advertisements from all types of mediums. In order to conduct the test, a group of respondents were invited in a comfortable room to view several commercials for all mediums. They were first given advertisements from newspaper, followed by magazines, radio, TV and Internet. Before viewing all the advertisements, each respondent is asked brand preference information about a number of product categories. After viewing the commercials and advertisements, respondents are again asked to express their brand preferences.

When the respondents completed the questionnaire and had been exposed to around 20-25 min of all types of advertisements from every type of mediums, they were given a second questionnaire and asked to record their recall of any advertisements that had been showed and played. They were asked a range of questions to examine their level of recall and preferences, ranging from whether or not they had heard any advertising at all, through to naming the brand that had been advertised. 
Table1: Model summary

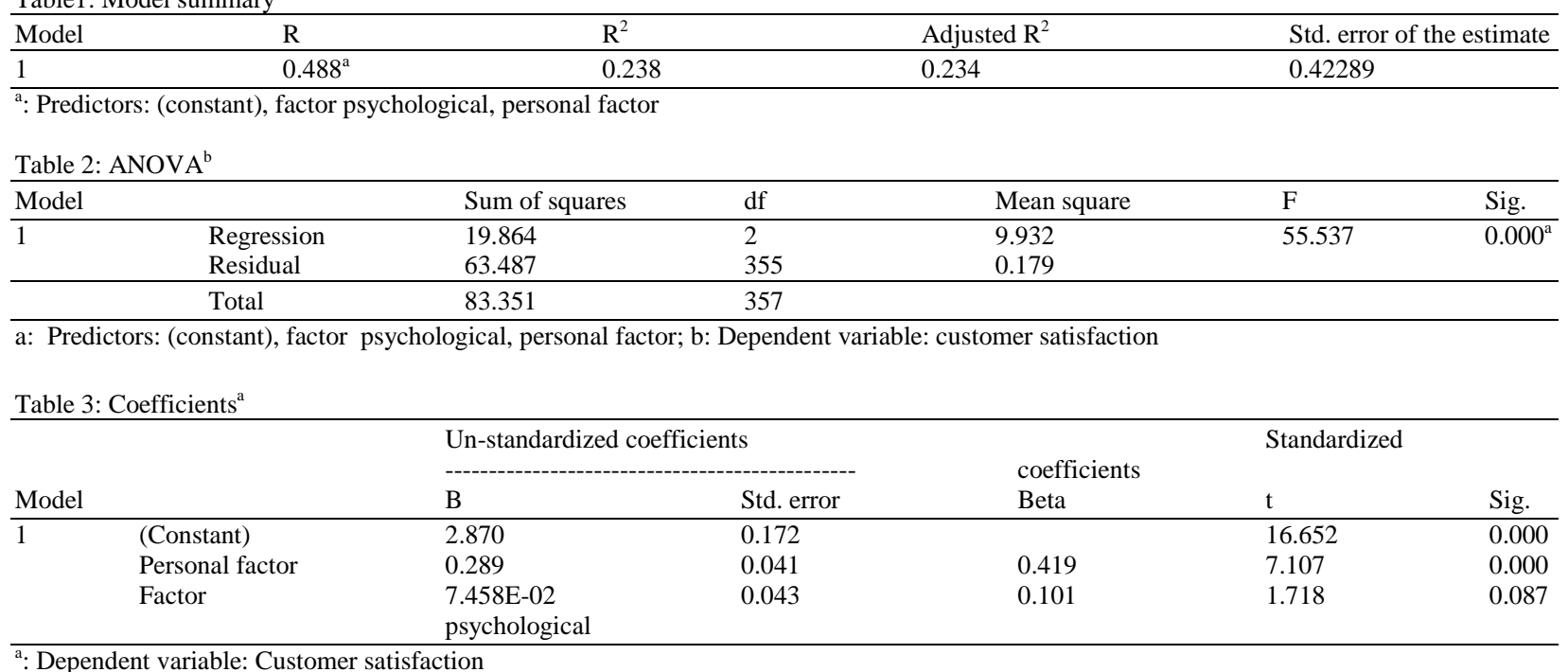

As encouragement to all respondents for their participation in the study, they were given a small token of gift (a set of stationeries) for completing the questionnaires. This is one way to encourage them to answer each of the questions properly. As for respondents in the experiment, they were given refreshments and a gift which contain tie for male respondents and purse for female respondents. This is to show an appreciation for their time and involvement in the study. To find out whether both factors have impact to the choice of advertising medium, regression analysis has been used.

\section{RESULTS}

Table 1 shows two independent variables which are personal factor and psychological factor which is the dimension of consumer behavior that are entered into the regression model and $\mathrm{R}=0.488, \mathrm{R}^{2}=0.238$. The ANOVA Table 2 shows that $F$ value of 55.537 is significant at 0.000 levels. The results show that around $24 \%$ of the variance $\left(\mathrm{R}^{2}\right)$ in customer satisfaction has been significantly explained by the two independent variables. From the coefficient Table 3 is shows that both personal and psychological factors have positive relationship with customer satisfaction. Between these two factors, personal factors has high level of significant relationship $(\mathrm{p}=0.000)$ compared to psychological factors $(\mathrm{p}=0.087)$.

\section{DISCUSSION}

The analysis shows that personal factors (such as gender and age) and psychological factors (e.g., status and personality) give an impact to customer satisfaction on the types of advertising media preferences. If both of these factors will create advertising beliefs, attitudes and the possibility of different consumer behavior, it is important for advertiser to identify and aware of consumers' interest in order to understand them better and able to design specific advertisements based on these both factors. Due to these factors, the advertiser may also pay attention to come out with attractive advertisements based on the trends. For example, youngsters may prefer more to TV commercials or Internet advertising compared to the older generation which may focus more on newspaper advertisements.

\section{CONCLUSION}

Consumers' can be sometimes ignorant or unaware about the existing product or services. This is where advertising can be a useful tools to attract consumers' attention and to inform them about the product and services. The magnetism of the advertising media may not only stimulate customers' satisfaction and interest at the advertisements but it may create purchase intention to buy the product and services. If the marketer able to decide the accurate media to advertise the product and services, this will help them to reduce advertising cost and make it more useful and helpful not only to them but also consumers. By understanding consumers' attitude towards advertising, designers and marketers can better strategize their advertising designs. A better understanding of interactivity can also help to improve the effectiveness of interactive media such as the Internet ${ }^{[10]}$. These attitudinal relations should play an essential role in consumer's decisions on which 
media to choose based on the benefits that the media provide.

Age, gender, personality and status will able to give impact to the choice of the advertising media. Consumers' will have their own preferences due to those factors. People are frequently confronted with so many brand names, persons, products and advertisements that they are unable to remember all these stimuli. However, an effect may be formed based on mere exposure without consciously recognizing or remembering the stimuli. Consumer behavior is one of the factors that create customer satisfaction. Advertising can awaken problem recognition and shift attitudes, both of which can result in repeat or change behavior ${ }^{[4]}$. The study also shows that males and females exhibit different beliefs and attitudes toward traditional media advertising and online advertising along with different advertising stimulated consumer behavior and satisfaction. If gendered advertising beliefs, attitudes and consumer behavior pattern exist, it is vital for advertisers to recognize them, understand them and use them to design gender specific advertisements ${ }^{[32]}$. Younger and older people have their own choice of advertising medium. Specific media may provide varying opportunity for person to consider the message content differently. In additional, personality and status of a person may determine the choice of advertising medium. Those who can afford to purchase mobile phones and TV will be different from those who unable to afford it. They might change to other medium such as radio and those who love reading will be aware advertisements from newspapers or magazines compared to those who hardly read. Overall, both factors will give impact on the choice of advertising medium.

\section{ACKNOWLEDGEMENT}

The researchers thank the university (Management and Science University) that funded the project.

\section{REFERENCES}

1. Adex-Analysis of Adex Size and Trend in Malaysia, 2006. Malaysian Communications and Multimedia Commission. Viewed on 23rd February 2008.

http://www.skmm.gov.my/what_we_do/Research/I ndustry\%20studies/Analysis_Adex_Size08.pdf

2. Barak, B., 1987. Cognitive age: A new multidimensional approach to measuring age identity. Int. J. Aging Hum. Develop., 25: 109-127. http://www.ncbi.nlm.nih.gov/pubmed/3436682
3. Barnes, S.J. and E. Scornavacca, 2004. Mobile marketing: the role of permission and acceptance. Int. J. Mobile Commun., 2: 128-139. http://portal.acm.org/citation.cfm?id=1360172

4. Barry, T.E., 2002. In defense of the hierarchy of effects: A rejoinder to Weilbacher. J. Advertis. Res., $\quad 42$ : 44-47. http://findarticles.com/p/articles/mi_hb3192/is_200 205/ai_n7866610/

5. Burns, K.S. and R.J. Lutz, 2006. The function of format: Consumers responses to six online advertising formats. J. Advertis., 35: 53. DOI: 10.2753/JOA0091-3367350104

6. Carat Interactive 2002. The Future of Wireless Marketing, a white paper viewed on 26th March 2008.

http://ebusinessforum.gr/content/downloads/Wirele ss_WhitePaper.pdf

7. Carroll, A., S.J. Barnes, E. Scornavacca and K. Fletcher, 2007. Consumer perceptions and attitudes towards SMS advertising: Recent evidence from New Zealand. Int. J. Advertis., 26: 79-98. http://direct.bl.uk/bld/PlaceOrder.do?UIN=204114 $387 \&$ ETOC $=$ RN \& from $=$ searchengine

8. Chang, C., 2008. Chronological age versus cognitive age for younger consumer-implications for advertising persuasion. J. Advertis., 37: 19-32. DOI: $10.2753 / \mathrm{JOA} 0091-3367370302$

9. Chang, C., 2007. The relative effectiveness of comparative and non-comparative advertisingevidence for gender differences. J. Advertis., 36: 21-35. DOI: 10.2753/JOA0091-3367360102

10. Chingning, W., Z. Ping, C. Risook and D. Michael, 2002. Understanding consumers attitude toward advertising. Proceeding of the 8th Americas Conference on Information Systems, Aug. 9-12, AIS-ICIS (Associate of Information System), Georgia State University, Atlanta, Georgia, pp: 1143-1148.

http://melody.syr.edu/hci/amcis02_minitrack/RIP/ Wang.pdf

11. Christy, T.P., 2006. Females perceptions of offensive advertising: The importance of values, expectations and control. J. Curr. Issues Res. Advertis., $\quad$ 28: 15-32. http://direct.bl.uk/bld/PlaceOrder.do?UIN=200312 040\&ETOC $=$ RN\& from $=$ searchengine

12. Courtney, A.E. and T.W. Whipple, 1974. Women in TV commercials. J. Commun., 24: 110-118. DOI: $10.1111 /$ j.1460-2466.1974.tb00375.x

13. Culley, J. and R. Bennett, 1976. Selling women, selling blacks. J. Commun., 26: 160-174. DOI: 10.1111/j.1460-2466.1976.tb01954.x 
14. Darke, P.R., L. Ashworth and J.B. Ritchie Robin, 2008. Damage from corrective advertising: causes and cures. J. Market., 72: 81-97. DOI: 10.1509/jmkg.72.6.81

15. Dickinger, A, P. Haghirian, J. Murphy and A. Scharl, 2004. An investigation and conceptual model of SMS marketing. Proceedings of the 37th Annual Hawaii International Conference on System Sciences, Jan. 05-08, IEEE Computer Society Washington, DC., USA., pp: 10031.2. DOI: 10.1109/HICSS.2004.1265096

16. Dominick, J.R. and G.E. Rausch, 1972. The image of women in network TV commercials. J. Broadcast., 16: 259-265.

17. Durkin, K., 1985a. Television and sex-role acquisition: I. content. Br. J. Soc. Psychol., 24: 101-113.

18. Friedman, H.H. and L. Friedman, 1979. Endorser effectiveness by product type. J. Advertis. Res., 19: 63-71.

19. Furnham, A., S. Abramsky and B. Gunter, 1997. A cross-cultural content analysis of children's television advertisements. Sex Roles, 37: 91-99. http://findarticles.com/p/articles/mi_m2294/is_n12_v37/ai_19965102/

20. Furnham, A. and E. Skae, 1997. Changes in the stereotypical portrayal of men and women in British television advertisements. Eur. Psychol., 2: 44-51.

http://direct.bl.uk/bld/PlaceOrder.do?UIN=024941 $723 \&$ ETOC $=$ RN\&from $=$ searchengine

21. Fortin, M., 2008. Psychology-the success doctor. Viewed on 22nd June 2008.

22. Garst, J. and G.V. Bodenhousen, 1997. Advertising's effects on men's gender role attitudes. Sex Roles, 36: 551-572. DOI: 10.1023/A:1025661806947

23. Gresko,J., L. Kennedy and J. Lesniak, 1996. Social psychological factors underlying the impact of advertising. Advanced Social Psychology. Viewed on $13^{\text {th }} \quad$ May 2008. http://www.users.muohio.edu/shermarc/p324ads.shtml

24. Heinonen, K. and T. Strandvik, 2003. Consumer responsiveness to mobile marketing. Proceedings of the Stockholm Mobility Roundtable, May 22-23, Stockholm, Sweden, pp: 603-607.

25. Jaishri, J. and J. Shruti, 2006. Advertising Management. Oxford University Press, New Delhi, ISBN: 13:978-0-19-567843-7, pp: 716.

26. Jelassi, T. and A. Enders, 2004. Leveraging wireless technology for mobile advertising. Proceedings of the 12th European Conference on Information Systems, June 14-16, Turku, Finland, pp: $1-11$.

http://is2.1se.ac.uk/asp/aspecis/20040075.pdf
27. Kelman, H.C., 1961. Processes of opinion change. Public Opin. Q., 25: 57-78. http://poq.oxfordjournals.org/cgi/content/abstract/2 $5 / 1 / 57$

28. Kinnear, T.C. and J.R. Taylor, 1996. Marketing Research-An Applied Approach. 5th Edn., McGraw Hill, North America, pp: 888.

29. Kolbe, R. and C. Langefeld, 1993. Appraising gender role portrayals in TV commercials. Sex Roles, 28: 393-417. DOI: 10.1007/BF00289604

30. Leppard, W., S.M. Ogletree and E. Wallen, 1993. Gender stereotyping in medical advertising: Much ado about something? Sex Roles, 29: 829-839. http://cat.inist.fr/?aModele $=$ afficheN\&cpsidt $=3881459$

31. Likert, Rensis, 1932. A technique for the measurement of attitudes. Arch. Psychol., 140: 1-55. http://en.wikipedia.org/wiki/Rensis_Likert

32. Lori, D.W and K. Pradeep, 2003. Web advertising: Gender differences in beliefs, attitudes and behavior. Int. Res. Elect. Network. Appli. Policy, 13: 375-385. DOI: 10.1108/106622403110501658

33. Lovdal, L.T., 1989. Sex role messages in television commercials: An update. Sex Roles, 21: 715-724. DOI: 10.1007/BF00289804

34. Maldonado, Rachel, Patriya Tansuhaj and D. Darell, 2003. The impact of gender on ad processing: A social identity perspective. Acad. Market. Sci. Rev., 3: 1-15.

http://www.amsreview.org/articles/maldonado032003.pdf

35. Malhotra, N.K., 2004. Marketing Research-An Applied Orientation. 4th Edn., Pearson Prentice Hall, New Jersey.

36. Milner, C., 2003. Six steps to age friendly advertising. The J. Active Aging. Viewed on 6th September 2008.

http://www.icaa.cc/member_salesandmarketing/ma rketing/sixstepstoagefriendlyads9.pdf

37. Neto, F. and I. Pinto, 1998. Gender stereotypes in portuguese television advertisements. Sex Roles, 39: 153-164.

http://cat.inist.fr/?aModele $=$ afficheN\&cpsidt=2394 646

38. O'Donnell, W.J. and K.J. O'Donnell, 1978. Update: Sex role messages in TV commercials. J. Commun., 28: 156-158. DOI: 10.1111/j.14602466.1978.tb01579.x

39. Okazaki, S., 2004. How do Japanese consumers perceive wireless ads? A multivariate analysis. Int. J. Advertis., 23: 429-454. http://media.researchhub.staging.ssrc.org/how-dojapanese-consumers-perceive-wireless-ads-amultivariate-analysis/resource_view 
40. Pearson, J.C., L.H. Turner and W. Todd-Mancillas, 1991. Gender and Communication. 2nd Edn., Wm. C. Brown Publisher, Dubuque, IA. ISBN: 10: 0697201546, pp: 332.

41. Rudman, W.J. and P. Verdi, 1993. Exploitation: Comparing sexual and violent imagery of females and males in advertising. Women Health, 20: 1-14. http://www.ncbi.nlm.nih.gov/pubmed/8171873

42. Severin, W.J. and J.W. Tankard, Jr., 1998. Communication Theories. 5th Edn., Longman, New York, pp: 3-21.

43. Signorelli, N., 1997. A study of television shows and commercials, movies, music videos and teen magazine articles and ads, sex roles. A. J. Res., 47: 1-30.

http://www.eric.ed.gov/ERICDocs/data/ericdocs $2 \mathrm{~s}$ q1/content_storage_01/0000019b/80/16/63/a6.pdf

44. Signorielli, N. and M. Lears, 1992. Children, television and conceptions about chores: Attitudes and behaviors. Sex Roles, 27: 157-170. DOI: 10.1007/BF00290015
45. Smith, L.J., 1994. A content analysis of gender differences in children's advertising. J. Broadcast. Elect. Media, 38: 323-337. http://direct.bl.uk/bld/PlaceOrder.do?UIN=019668 $680 \& \mathrm{ETOC}=\mathrm{EN} \&$ from $=$ searchengine

46. William, W., M. Sandra, B. John and L. May, 2007. Advertising-Principles and Effective IMC Practice. Pearson Prentice Hall, Singapore, ISBN: 978-013-167660-2, pp: 641.

47. Williamson, J., 1978. Decoding Advertisements. Marion Boyars, London, pp: 117-139.

48. Wilson, T.D. and S.D. Hodges, 1992. Attitudes as Temporary Constructions. In: The Construction of Social Judgments, Martin, L.L. and A. Tesser (Eds.). Erlbaum, Hillsdale, NJ., pp: 37-65.

49. Yarborough Melanie 2008. Gender-pitched advertising: Do men and women see the same things? [WWW document]. http://village.fortunecity.com/carnival/383/index.ht m\#melanie 